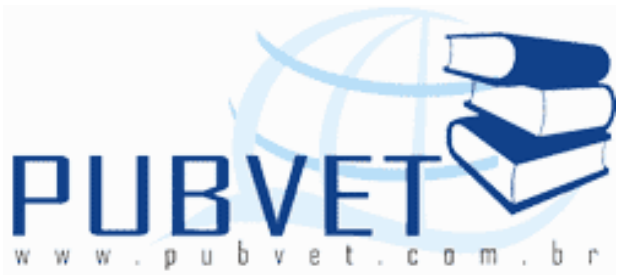

PUBVET, Publicações em Medicina Veterinária e Zootecnia.

\title{
Efeitos da utilização de ácidos orgânicos em rações de frangos de corte
}

Pascoal Funari Junior ${ }^{1}$, Adriele Nayara Dias Ishizuka ${ }^{2}$, Rayane Sol Amaral Silva ${ }^{2}$, Aline de Oliveira Rodrigues ${ }^{2}$, Aline Cassacchi Mariussi ${ }^{2}$, Valdomiro Pereira $^{3}$, Isabella Goulart Oliveira da Silva², Viviane Alcântara da Silva ${ }^{2}$

${ }^{1}$ Docente do Departamento de Medicina Veterinária da Universidade Estadual de Maringá.

${ }^{2}$ Graduandas do curso de Medicina Veterinária da Universidade Estadual de Maringá

${ }^{3}$ Técnico do Departamento de Medicina Veterinária da Universidade Estadual de Maringá.

\section{Resumo}

O presente trabalho teve como objetivo avaliar as conseqüências da substituição de antibióticos promotores de crescimento por ácidos orgânicos em dietas de frangos de corte. Foram utilizados 280 pintos de 1 dia, machos, de linhagem. O delineamento experimental foi inteiramente casualisado, com 5 tratamentos e 7 repetições com 8 aves em cada. Os tratamentos utilizados foram: T1(controle negativo, sem aditivos), T2 (Ac. láctico, propiônico e fórmico), T3 (Ac. fumárico, fórmico, propiônico e sórbico), T4 (Ac. láctico e fórmico, fumárico e cítrico), T5 (controle positivo, adição de antibiótico promotor de crescimento). O peso das aves e o consumo de ração foram quantificados através de controles realizados nas diferentes fases de 
FUNARI JUNIOR, P. et al. Efeitos da utilização de ácidos orgânicos em rações de frangos de corte. PUBVET, Londrina, V. 5, N. 25, Ed. 172, Art. 1159, 2011.

desenvolvimento: inicial, crescimento e terminação. Aos 42 dias de idade, duas aves de cada repetição, 14 de cada tratamento foram retiradas da unidade experimental e abatidas para avaliação do rendimento de carcaça total, rendimento de peito, rendimento de perna. Os resultados mostraram que os ácidos orgânicos não têm influencia sobre o rendimento de carcaça e dos cortes. Quanto ao desempenho zootécnico, este deve ser mais bem avaliado, pois possivelmente as condições experimentais podem não permitir o desafio necessário para que aditivos como ácidos orgânicos e antibióticos mostrem seu potencial.

Palavras-chave: antibiótico promotor de crescimento, desempenho, rendimento

\title{
Effects of organic acids in broiler diets
}

\begin{abstract}
This study aimed to evaluate the consequences of replacing growth promoter antibiotics by organic acids in diets of broilers. A completely randomized design was utilized, with 5 treatments ( $T 1$ : negative control without antibiotics or organic acids; T2: latic, propionic and formic acids; T3: fumaric, formic, propionic and sorbic acids; T4: lactic, formic, fumaric and citric acids; T5: positive control, addition of antibiotic) and 7 replicates of 8 birds per experimental units. To evaluate de performance, the weight and feed intake were measured at different stages (1-21; 21-35; 35-42 day old). At 42 day old, 2 birds per pen were sacrificed with human methods to evaluate carcass yield, breast yield and leg yield. The results showed that organic acids have no influence on carcass yield and cuts. The performance should be better evaluated, because the experimental conditions don't offer an enough environmental challenge for the additives (antibiotics and organic acids) can show their potential.
\end{abstract}

Keywords: organic acid, growth promoters, performance, broiler chicken 
FUNARI JUNIOR, P. et al. Efeitos da utilização de ácidos orgânicos em rações de frangos de corte. PUBVET, Londrina, V. 5, N. 25, Ed. 172, Art. 1159, 2011.

\section{INTRODUÇÃO}

A globalização da avicultura tem ocasionado mudanças importantes na produção de frangos. O comércio internacional de produtos finais vem acompanhado da crescente influencia da opinião pública, a qual é formada por pressão de grupos organizados, televisão, acesso à Internet entre outros aspectos. São conhecidas as necessidades de consumo da Europa, Japão e países árabes e a influência que causam nos aspectos relativos a produção de frangos, tais como: o não uso de antibióticos promotores de crescimento, sem uso de drogas restritivas na produção (e.g. nicarbazina, nitrofuranos), ou ainda, com abate orientado para crenças religiosas (BELLAVER e SCHEUERMANN, 2004).

Com a proibição do uso de antibiótico pela união européia em janeiro de 2006, a busca por produtos que mantenham o desempenho e sejam aceitáveis foi intensificada. Este fato fez com que a pesquisa na área de nutrição das aves partisse em busca de compostos que se enquadrassem nestas qualidades. A comunidade científica tem testado diversos substitutos para o uso de antibióticos e os ácidos orgânicos parecem ser uma alternativa. Os produtos substitutivos precisam ser seguros, efetivos, baratos e fáceis de usar, sem descuidar-se que há necessidade de melhoria do manejo geral.

Os ácidos orgânicos e os antibióticos têm sido utilizados como aditivos de rações animais para melhorar o desempenho das aves. A acidificação dos alimentos tem potencial para controlar bactérias, podendo melhorar 0 crescimento e a eficiência alimentar, eliminando microrganismos que competem por nutrientes. Benefício semelhante é atribuído aos antibióticos; entretanto, os acidulantes não deixam resíduos na carcaça e não promovem o aparecimento de bactérias resistentes (MILLER, 1987).

Segundo Adams (1999) as funções dos ácidos orgânicos são variadas e amplas, nem todas relacionadas à nutrição. Produzem acidez, a qual por sua vez age como flavorizante e também retarda a degradação enzimática. Atuam como agentes quelantes que se ligam a metais formando os queleatos metálicos, os quais previnem ou reduzem a oxidação oriunda da catálise dos 
FUNARI JUNIOR, P. et al. Efeitos da utilização de ácidos orgânicos em rações de frangos de corte. PUBVET, Londrina, V. 5, N. 25, Ed. 172, Art. 1159, 2011.

metais-ions. Agem diretamente como fortes inibidores do crescimento microbiano podendo ter uso na preservação de grãos e rações, sanitização da carne e como aditivo promotor de crescimento na ração.

Os ácidos orgânicos possuem o poder bacteriostático e bactericida gramnegativo in vitro, desde que presente em quantidade suficiente e por tempo adequado. As hipóteses que sustentam a utilização destes ácidos são o poder inibidor no desenvolvimento de fungos, proliferação de enterobactérias e como potencializador, aumentando a disponibilidade dos nutrientes para as aves (PENZ et al.,1993).

Os ácidos orgânicos de diferentes classes (fórmico, láctico, propiônico, acético, cítrico, butírico, e outros) têm sido amplamente utilizados na avicultura, por tornar-se uma alternativa aos antibióticos promotores do crescimento substituindo-os onde provocam um efeito bacteriostático ou bactericida dependendo da bactéria (FERREIRA \& ASTOLFI-FERREIRA, 2006). A ação do ácido reduz o pH e conseqüentemente a flora patogênica, evitando a destruição das vilosidades intestinais, mantendo a espessura da parede do intestino e da membrana da mucosa normal, aumentando a absorção integral dos nutrientes (VETANCO, 2005).

Garcia et. al (2000) relatam que não houve diferença significativa no desempenho de frangos de corte aos 45 dias de idade, alimentados com ração contendo ou não apramicina, ácidos orgânicos (fórmico e propiônico), e associação de apramicina com os ácidos. Albuquerque et. al (1998) diz que os ácidos orgânicos apresentaram comportamento irregular em termos de atividade bactericida em rações artificialmente contaminadas por Salmonella spp. Contrariando está afirmação, Bassan e Flôres (2006) obtiveram resultados em que a utilização de ácidos orgânicos foi eficiente no controle da infecção por Salmonella enteretidis.

\section{MATERIAL E MÉTODOS}

O experimento foi conduzido no aviário experimental do Centro de Ciências Agrárias da Universidade Estadual de Maringá, campus de 
FUNARI JUNIOR, P. et al. Efeitos da utilização de ácidos orgânicos em rações de frangos de corte. PUBVET, Londrina, V. 5, N. 25, Ed. 172, Art. 1159, 2011.

Umuarama. Foram utilizadas baterias, com 36 divisões e a criação das aves até os 42 dias de idade.

O experimento foi realizado com 280 pintos de 1 dia, machos, de linhagem comercial especializada para corte. O delineamento experimental foi inteiramente casualisado, com 5 tratamentos e 7 repetições/tratamento. Assim sendo os animais foram distribuídos em 35 parcelas com 8 aves em cada uma. Os tratamentos utilizados foram:

$>$ T1: controle negativo, sem aditivos;

> T2: Ac. láctico, propiônico e fórmico;

> T3: Ac. fumárico, fórmico, propiônico e sórbico;

> T4: Ac. láctico e fórmico, fumárico e cítrico;

> T5: controle positivo, adição de antibiótico promotor de crescimento (bacitracina de zinco).

Para o tratamento com ácidos livres foi utilizado o produto comercial Oligo $A c i d \AA$, que é composto por $9 \%$ de ácido lático, $15 \%$ de ácido propiônico e $23,5 \%$ de ácido fórmico, sendo adicionado $3 \mathrm{~kg}$ do produto por tonelada de ração. O tratamento com ácidos protegidos utilizou o produto comercial Galliacid ${ }^{\circledR}$, que é composto por $25 \%$ de ácido fumárico, $8 \%$ fórmico, $4 \%$ propiônico e $2 \%$ sórbico e $61 \%$ de óleo vegetal que tem a função de proteger os ácidos para que a maior atuação ocorra no intestino. Foi utilizado $600 \mathrm{~g}$ deste produto para cada tonelada de ração. Para o tratamento com ácidos livres e protegidos foi utilizado o produto comercial $\mathrm{NeoAcid} \Omega$, que é composto por $37 \%$ de ácidos orgânicos de cadeia curta sendo lático >fórmico>cítrico>fumárico, $37 \%$ de gorduras. Foi utilizado $1 \mathrm{~kg}$ deste produto por tonelada de ração.

As rações eram isoprotéicas e isocalóricas, elaboradas a base de milho e soja cuja formulação obedeceu aos níveis nutricionais rotineiramente praticados na criação comercial de frangos de corte. A alimentação foi diferenciada quanto aos níveis de proteína e energia em três fases de desenvolvimento: inicial, crescimento e final. A ração, assim como a água será 
FUNARI JUNIOR, P. et al. Efeitos da utilização de ácidos orgânicos em rações de frangos de corte. PUBVET, Londrina, V. 5, N. 25, Ed. 172, Art. 1159, 2011.

fornecida ad libitum do $1^{\circ}$ ao $42^{\circ}$ dia de vida. A composição da ração e a análise calculada dos nutrientes estão apresentadas na tabela 1. Os ácidos e o antibiótico entraram na composição das rações substituindo o caulin, na proporção indicada acima para cada produto.

Tabela 1 - Composição porcentual e análise calculada das rações nas diferentes fases de criação.

\begin{tabular}{lccc}
\hline \hline Ingredientes & Inicial & Crescimento & Final \\
\hline Milho & 52,26 & 57,11 & 63,7 \\
Farelo de Soja & 40,13 & 34 & 28 \\
Óleo de Soja & 3,52 & 4.9 & 4,5 \\
Sal & 0,35 & 0,35 & 0,35 \\
Calcário & 1,24 & 1,6 & 1,6 \\
Fosfato Bicálcico & 1,6 & 1,14 & 0,95 \\
Metionina & 0,24 & 0,21 & 0,18 \\
Suplemento Vit.-Min. ${ }^{(1)}$ & 0,4 & 0,4 & 0,4 \\
Caulin & 0,26 & 0,29 & 0,32 \\
\hline Total & 100 & 100 & 100 \\
\hline & & & \\
\hline \hline ANÁLISE CALCULADA & & & 3150 \\
\hline Energia $\quad$ Metaolizável & 2950 & 3100 & 18,0 \\
(Kcal/Kg) & 22,5 & 20,0 & 0,30 \\
Proteína (\%) & 0,35 & 0,32 & 0,60 \\
Metionina (\%) & 0,71 & 0,65 & 0,90 \\
Metionina + Cistina (\%) & 0,95 & 0,95 & 0,30 \\
Cálcio (\%) & 0,45 & 0,35 & \\
Fósforo Disponível (\%) & & & \\
\hline
\end{tabular}

(1) Premix vitamínico e mineral adequado a cada fase de desenvolvimento. 
FUNARI JUNIOR, P. et al. Efeitos da utilização de ácidos orgânicos em rações de frangos de corte. PUBVET, Londrina, V. 5, N. 25, Ed. 172, Art. 1159, 2011.

A fim de determinar as variáveis de desempenho seguintes, o peso das aves e o consumo de ração foram quantificados através de controles realizados nas diferentes fases de desenvolvimento: inicial ( 1 a 21 dias de vida); crescimento (21 a 35 dias de vida) e terminação (35 a 42 dias de vida). Variáveis respostas:

- Ganho de peso médio (GPM), em gramas, para cada parcela: determinado pela diferença entre as pesagens das aves no fim e início de cada fase dividida pelo número de animais.

- Consumo de ração (CR), em gramas, para cada parcela: obtido pela diferença entre a quantidade de ração fornecida (início da fase) e a sobra (final da fase) dividida pelo número de aves.

- Conversão alimentar (CA), para cada parcela: obtida pela relação entre o consumo total de ração no final de cada fase e o seu respectivo ganho de peso ( $g$ de ração/g de ganho).

Aos 42 dias de idade, duas aves de cada repetição, 14 de cada tratamento foram retiradas da unidade experimental e abatidas para avaliação do rendimento de carcaça total ( $R C)$, rendimento de peito (RP), rendimento de perna (coxa + sobre coxa).

Os dados obtidos foram submetidos a análise estatística com auxílio do programa computacional Static Graphic, o teste de média adotado foi o Tukey com nível de significância de 5\%.

\section{RESULTADOS E DISCUSSÃO}

Os resultados obtidos estão apresentados nas tabelas 2, 3, 4, 5 e 6 . 
FUNARI JUNIOR, P. et al. Efeitos da utilização de ácidos orgânicos em rações de frangos de corte. PUBVET, Londrina, V. 5, N. 25, Ed. 172, Art. 1159, 2011.

Tabela 2 - Parâmetros de desempenho aos 21 dias de vida.

\begin{tabular}{lccccc}
\hline Tratamentos & Peso & $\begin{array}{c}\text { Ganho de } \\
\text { Peso }\end{array}$ & $\begin{array}{c}\text { Ganho } \\
\text { Médio } \\
\text { Diário }\end{array}$ & $\begin{array}{c}\text { Consumo de } \\
\text { Ração }\end{array}$ & $\begin{array}{c}\text { Conversão } \\
\text { Alimentar }\end{array}$ \\
\hline T1 & 874,148 & 822,845 & 39,18 & 1033,92 & 1,3151 \\
T2 & 853,978 & 802,678 & 38,22 & 1022,80 & 1,2771 \\
T3 & 868,752 & 817,445 & 38,92 & 1017,92 & 1,2449 \\
T4 & 826,043 & 774,740 & 36,89 & 1028,33 & 1,3270 \\
T5 & 861,933 & 810,633 & 38,60 & 1082,25 & 1,2756 \\
\hline \hline
\end{tabular}

Tabela 3 - Parâmetros de desempenho aos 35 dias de vida.

\begin{tabular}{lccccc}
\hline Tratamentos & Peso & $\begin{array}{c}\text { Ganho de } \\
\text { Peso }\end{array}$ & $\begin{array}{c}\text { Ganho } \\
\text { Médio } \\
\text { Diário }\end{array}$ & $\begin{array}{c}\text { Consumo de } \\
\text { Ração }\end{array}$ & $\begin{array}{c}\text { Conversão } \\
\text { Alimentar }\end{array}$ \\
\hline T1 & 1972,63 & 1921,30 & 54,89 & 2883,83 & 1,5042 \\
T2 & 1993,18 & 1941,88 & 55,48 & 2819,17 & 1,4514 \\
T3 & 1964,47 & 1913,17 & 54,66 & 2763,96 & 1,4459 \\
T4 & 1843,75 & 1792,44 & 51,21 & 2665,83 & 1,4870 \\
T5 & 1935,99 & 1884,68 & 53,84 & 2732,21 & 1,4481 \\
\hline \hline
\end{tabular}

Tabela 4 - Parâmetros de desempenho aos 42 dias de vida.

\begin{tabular}{lccccc}
\hline \hline Tratamentos & Peso & $\begin{array}{c}\text { Ganho de } \\
\text { Peso }\end{array}$ & $\begin{array}{c}\text { Ganho } \\
\text { Médio } \\
\text { Diário }\end{array}$ & $\begin{array}{c}\text { Consumo } \\
\text { de Ração }\end{array}$ & $\begin{array}{c}\text { Conversão } \\
\text { Alimentar }\end{array}$ \\
\hline T1 & $2362,03 \mathrm{~b}$ & $2310,73 \mathrm{~b}$ & $55,01 \mathrm{~b}$ & 3952,01 & 1,7137 \\
T2 & $2424,62 \mathrm{~b}$ & $2373,32 \mathrm{~b}$ & $56,50 \mathrm{~b}$ & 3888,15 & 1,6374 \\
T3 & $2254,07 \mathrm{ab}$ & $2202,77 \mathrm{ab}$ & $52,44 \mathrm{ab}$ & 3761,88 & 1,7087 \\
T4 & $2167,71 \mathrm{a}$ & $2116,41 \mathrm{a}$ & $50,39 \mathrm{a}$ & 3665,83 & 1,7329 \\
T5 & $2307,53 \mathrm{ab}$ & $2256,22 \mathrm{ab}$ & $53,72 \mathrm{ab}$ & 3780,13 & 1,6738 \\
\hline
\end{tabular}

Letras diferentes na mesma coluna diferem estatisticamente. 
FUNARI JUNIOR, P. et al. Efeitos da utilização de ácidos orgânicos em rações de frangos de corte. PUBVET, Londrina, V. 5, N. 25, Ed. 172, Art. 1159, 2011.

Como pode-se observar nas tabelas 2 e 3, não houve diferença estatística entre os tratamentos até os 35 dias de idade. Já a tabela 4 mostra diferença entre os tratamentos nos parâmetros peso, ganho de peso (GP) e ganho médio diário (GMD), não ocorrendo o mesmo para o consumo de ração e conversão alimentar. O T4 apresentou menor valor para os três parâmetros citados quando comparado com o T1 e T2, porém não se diferenciou de T3 e T5.

Este resultado não condiz com o apresentado por Garcia et al. (2000) e Maiorka et al (2004) onde ambos observaram diferenças aos 21 dias de idade quando utilizaram tratamentos semelhantes. Campos et al. (2004) trabalhando com o ácido orgânico fumárico, não encontraram diferenças para o peso das aves no período final de criação. Resultados semelhantes foram encontrados por Runho (1995) que encontrou pesos semelhantes na fase final de criação de frangos de corte quando comparou dietas com ou sem ácido.

Leeson et al. (2005) observaram efeito dos ácidos fosfórico, cítrico e butírico similares ao de antibióticos promotores de crescimento sobre o ganho de peso e a conversão alimentar de frangos de corte. Esses autores sugeriram que os acidificantes auxiliam na manutenção da integridade intestinal por reduzirem os desafios microbiológicos sobre a mucosa, melhorando a capacidade de utilização do alimento pelos animais e reduzindo os gastos de manutenção dos tecidos intestinais. Como benefício geral desta melhora, observa um impacto positivo na conversão alimentar (LEESON et al., 2005).

$\mathrm{O}$ fato de T2 ter obtido melhor peso, GP e GMD quando com parado a T4 levanta a possibilidade de que a diferença na apresentação e composição dos ácidos de cada tratamento possa interferir no desempenho das aves. Por outro lado o fato do tratamento controle obter resultados semelhantes aos T2, T3 e T5 mostra a necessidade de se realizar pesquisas com um desafio sanitário mais elevado, propiciando um meio semelhante ao encontrado no campo para que se possa afirmar que estes produtos têm ou não condições de substituir os antibióticos promotores de crescimento. 
FUNARI JUNIOR, P. et al. Efeitos da utilização de ácidos orgânicos em rações de frangos de corte. PUBVET, Londrina, V. 5, N. 25, Ed. 172, Art. 1159, 2011.

Tabela 5 - Peso vivo, limpo e dos cortes.

\begin{tabular}{lcccc}
\hline Tratamentos & Peso Vivo & Peso Limpo & Peso Peito & Peso Perna \\
\hline T1 & 2318,75 & 2018,75 & 601,75 & 501,25 \\
T2 & 2387,50 & 2068,50 & 625,25 & 511,00 \\
T3 & 2243,75 & 1956,50 & 558,00 & 511,00 \\
T4 & 2193,75 & 1931,75 & 582,75 & 479,00 \\
T5 & 2300,00 & 2023,50 & 607,50 & 491,00 \\
\hline \hline
\end{tabular}

Tabela 6 - Rendimentos de carcaça e cortes.

\begin{tabular}{lccc}
\hline \hline Tratamentos & $\begin{array}{c}\text { Rendimento } \\
\text { Carcaça }\end{array}$ & $\begin{array}{c}\text { Rendimento de } \\
\text { Peito }\end{array}$ & Rendimento Perna \\
\hline T1 & 87,0313 & 25,9013 & 21,5988 \\
T2 & 86,6375 & 26,1488 & 21,4488 \\
T3 & 87,2313 & 24,8725 & 22,7837 \\
T4 & 88,0513 & 26,5062 & 21,8350 \\
T5 & 87,9925 & 26,4150 & 21,3663 \\
\hline \hline
\end{tabular}

Quanto às avaliações de carcaça não houve nenhuma diferença entre os tratamentos. Waldroup et al. (1991) utilizaram em seus trabalhos o ácido fumárico e constataram que não houve efeito desse ácido sobre o rendimento de carcaça das aves. Faria et al. (2009) também não observou efeito dos ácidos orgânicos sobre o rendimento de carcaça e cortes. Henrique et al. (1998) utilizaram um composto de $45 \%$ de ácido propiônico e 15\% de ácido fórmico em frangos até os 42 dias de idade com inclusão de $0,05 \%$ na dieta tendo sido constatado a falta de efeito significativo sobre a performance e características de carcaça. E também Mizubuti et al. (1998) que não encontraram nenhum efeito significativo $(P>0,05)$ nas características de carcaça de frangos de 1 a 42 dias de idade, com dietas contendo até $1 \%$ de ácido acético. 
FUNARI JUNIOR, P. et al. Efeitos da utilização de ácidos orgânicos em rações de frangos de corte. PUBVET, Londrina, V. 5, N. 25, Ed. 172, Art. 1159, 2011.

\section{CONCLUSÃO}

O rendimento de carcaça e cortes não é influenciado pela utilização de ácidos orgânicos.

São necessárias maiores investigações para realmente se conhecer como a utilização dos ácidos orgânicos pode influenciar desempenho zootécnico de frangos de corte. É necessário a adequação das condições experimentais, para que estas ofereçam desafio semelhante ao encontrado no campo pra que se possa realmente avaliar a capacidade dos ácidos em substituir os antibióticos promotores de crescimento, e em quais condições de criação isto seria possivel.

\section{REFERÊNCIAS}

ADAMS, C. A. Nutricines. Food components in Health and Nutrition. Nottingham Univ. Press. Nottingham 1999.

ALBUQUERQUE, R.; ITO, N.M.K.; MIYAJI, C.I. Tratamento de rações de aves com ácidos orgânicos: estudo da atividade bacteriana e avaliação de técnicas de recuperação de Salmonella spp. Braz. J. vet. Res. anim. Sci., São Paulo, v. 35, n. 6, p. 279-282, 1998.

BASSAN, J.D.L.; FLÔRES, M.L. Avaliação de dois ácidos orgânicos incorporados em um "carrier" mineral no controle da infecção por Salmonella Enteretidis em frangos de corte. Programa de Pós graduação da Universidade Federal de Santa Maria, disponível no endereço http://coralx.ufsm.br/ppgmv/SEMINARIOS2006/Joana Darc.pdf acessado em 20/08/2008.

BELLAVER, C.; SCHEUERMANN, G. Aplicações dos ácidos orgânicos na produção de aves de corte. Palestra apresentada na Conferencia AVISUI 2004. Florianópolis SC, 2004

FARIA, D.E.; HENRIQUE, A.P.F; FRANZOLIN NETO, R.; MEDEIROS, A.A.; JUNQUEIRA, O.M.; FARIA FILHO, D.E. Alternativas ao uso de antibióticos como promotores de crescimento para frangos de corte: 2. Ácidos orgânicos e probióticos. Ciência Animal Brasileira. vol 10, n1, 2009.

HENRIQUE, A. P. F. ; FARIA, D. E. ; FRANZOLIN NETO, R. ; ITO, D. T. ; RODRIGUES, P. H. M.. Efeito de ácido orgânico, probiótico e antibiótico sobre o desempenho e rendimento de carcaça de frangos de corte. Anais da XXXV Reunião da SBZ, Botucatu/SP, 1998.

GARCIA, R.G.; ARIKI, J.; MORAES, V.M.B.; KRONKA, S.N.; BORGES, S.A.; MURATA, L.S.; CAMPOS, V.A. Ação Isolada ou Combinada de Ácidos Orgânicos e Promotor de Crescimento em Rações de Frangos de Corte. Rev. Bras. Cienc. Avic. vol.2 no.2 Campinas, 2000.

LEESON, S.; NAMKUNG, H.; ANTONGIOVANNI, M. et al. Effect of butiric acid on the performance and carcass yield of broiler chickens. Poultry Science, v.84, p.1418-1422. 2005. 
MAIORKA, A.; SANTIN, A.M.E.; BORGES, S.A.; OPALINSKI, M.; SILVA, A.V.F. Emprego de uma mistura de ácidos fumárico, lático, cítrico e ascorbico em dietas iniciais de frangos de corte. Archives of Veterinary Science v. 9, n. 1, p. 31-37, 2004

MILLER, D. F. Acidified poultry diets and their implications for the poultry industry. In: Biotechnology in the feed industry - Alltech technical; 1987; p.199-207.

MIZUBUTI, I.Y.; RIBEIRO, E.L.A.; ROCHA, M.A.; DANGUI, I.P.; MENDES, A.R. ; NORONHA, A.R.. Avaliação do rendimento de carcaça de frangos de corte alimentados com diferentes níveis de ácido acético na ração. Anais da XXXV Reunião da SBZ, Botucatu/SP, 1998.

MONTEIRO, A.C. Utilização de antibióticos e ácidos orgânicos em rações de frangos de corte, Dissertação (mestrado), Programa de Pós-Graduação em Zootecnia da Universidade Estadual de Maringá, 2007.

PENZ, A.M.; SILVA, A.; RODRIGUES, O. Ácidos orgânicos na alimentação de aves. In: Conferência Apinco de Ciência e Tecnologia Avícolas; Santos, São Paulo. Brasil: FACTA 1993; p.111-9.

VETANCO, B. Salkil. Chapecó(SC), 2005. 8p. (Boletim Técnico,8)

WALDROUP PW, SKINNER JT, IZAT AL. Fumaric acid embrances performance of broiler chickens. Poultry Science 1991; 70: 1444-7. 